\title{
OTOLOGY
}

\section{Cochlear obliteration following a translabyrinthine approach and its implications in cochlear implantation}

\author{
Ossificazione cocleare dopo l'approccio translabirintico e le sue implicazioni \\ per l'impianto cocleare
}

\author{
B. DELGADO-VARGAS, M. MEDINA, R. POLO, A. LLORIS, M. VACA, C. PÉREZ, A. CORDERO, I. COBETA \\ Department of Otolaryngology and Head and Neck Surgery, Hospital Universitario Ramón y Cajal, Ctra. de \\ Colmenar Viejo, Madrid, Spain
}

\section{SUMMARY}

The most frequent sequelae following a translabyrinthine approach for vestibular schwannoma resection is complete hearing loss on the affected side. Such patients could benefit from a cochlear implant, provided that two essential requisites are met before surgery: a preserved cochlear nerve and a patent cochlea to accommodate the electrode array. The goal of our study is to determine the prevalence and extent of cochlear ossification following a translabyrinthine approach. Postoperative MRI of 41 patients were retrospectively reviewed. Patients were classified according to the degree of cochlear obliteration into three groups (patent cochlea, partially obliterated cochlea and totally obliterated cochlea). The interval between surgery and the first MRI was studied as well as its relationship with the rate of cochlear ossification. At first postoperative MRI (mean interval of 20 months), 78\% of patients showed some degree of cochlear ossification. Differences were found in the time interval between surgery and first MRI for each group, showing a smaller interval of time the patent cochlea group ( $p>0.05$ ). When MRI was performed before the first year after surgery, a larger rate of patent cochlea was found ( $p>0.05$ ). The present study suggests that cochlear ossification is a time-depending process, whose grounds are still to be defined.

KEY WORDS: Cochlear obliteration • Translabyrinthine approach • Vestibular schwannoma • Cochlear implant

\section{RIASSUNTO}

La conseguenza piú frequente dopo un approccio translabirintico per uno schwannoma vestibolare è la completa perdita uditiva dal lato affetto. Questi pazienti possono trarre beneficio da un impianto cocleare, qualora però vengano soddisfatti due importanti requisiti prima della chirurgia: un nervo cocleare intatto e una coclea permeabile per accomodare l'elettrodo. L'obiettivo del nostro studio è quello di determinare la prevalenza e l'estensione dell'ossificazione cocleare dopo l'approccio translabirintico. Pertanto, sono state rivisitate retrospettivamente le immagini della risonanza magnetica (RM) post-chirurgica di 41 pazienti. I pazienti sono stati classificati secondo il grado di obliterazione cocleare in tre gruppi (coclea permeabile, coclea parzialmente obliterata e coclea completamente obliterata). $\dot{E}$ stato studiato l'intervallo tra la chirurgia e la prima RM post-chirurgica ed anche la sua relazione con il tasso di ossificazione cocleare. Alla prima RM post-chirurgica (intervallo medio: 20 mesi), il $78 \%$ dei pazienti ha mostrato un certo grado di obliterazione cocleare. Sono state trovate differenze nell'intervallo di tempo tra la chirurgia e la prima RM per ogni gruppo, mostrandosi l'intervallo di tempo piú breve nel gruppo con la coclea permeabile ( $p>0,05$ ). Questo studio suggerisce, quindi, che l'ossificazione cocleare è un processo tempo-dipendente, rimanendo, peró, i motivi di ció ancora sconosciuti.

PAROLE CHIAVE: Ossificazione cocleare $・$ Approccio translabirintico $\bullet$ Schwannoma vestibolare $・$ Impianto cocleare

Acta Otorhinolaryngol Ital 2018;38:56-60

\section{Introduction}

A translabyrinthine approach (TLA) for the resection of a vestibular schwannoma (VS) results invariably in complete hearing loss. This symptom is the most common complaint after VS surgery ${ }^{1}$. Hearing rehabilitation of these patients has traditionally relied on crossover or bone conduction hearing aids. In 1988, Chen et al. ${ }^{2}$ demonstrated the presence of survival spiral ganglion after a labyrinthectomy in a comparable number to those found in patients with a CI. More recently, several studies have shown that these pa- 
tients can be good candidates for cochlear implantation provided that the cochlear nerve has been anatomically and functionally preserved ${ }^{3}$. However, another requisite for cochlear implantation is the presence of a patent cochlea, capable of accommodating an electrode array. Cochlear ossification depends on different phenomenon of fibrosis or ossification derived from the violation of the otic capsule ${ }^{4}$. The surgical insult to this structure may produce either a vascular compromise or an inflammatory process such as a labyrinthitis that derives in a cochlear degeneration.

The lack of cochlear patency limits hearing rehabilitation with cochlear implants (CI), especially when there is a notable delay between the VS removal and the CI surgery. Even though a CI insertion in an obliterated cochlea is achievable, it becomes a more challenging surgery and hearing outcome may be less than expected ${ }^{56}$; this is the reason why the presence of an obliterated cochlea is generally considered as a contraindication to implantation. Some authors advocate for simultaneous implantation or sequential cochlear implantation soon after the TLA to prevent this problem. Computerised tomography scan (CT) has demonstrated to be useful to study cochlear anatomy and electrode position in cochlear implantation, although it has important limitations to assess the cochlear patency ${ }^{7}$.

In order to study this phenomenon, magnetic resonance imaging (MRI) is the best imaging modality to determine cochlear patency and fibrous or osseous changes on it ${ }^{89}$. It possesses a sensitivity of almost $100 \%$ in predicting cochlear obstruction and is routinely used for this reason preceding a CI insertion ${ }^{10}{ }^{11}$. However, the number of studies determining the rate of cochlear obliteration after TLA are scarce, and their results are contradicting. Furthermore, no study has been able to establish a "safe" time interval between the TLA and the cochlear obliteration to date; nonetheless, it is widely accepted that the sooner the CI is inserted, the better the hearing outcomes to be expected.
The aim of this study was to determine the prevalence and extent of cochlear obliteration after a TLA for VS removal, examining routine follow-up MRI studies performed as part of postoperative monitoring.

\section{Materials and methods}

This study was conducted according to the principles stated in the Declaration of Helsinki of 1983.

Sixty-nine patients that underwent a TLA for removal of a unilateral sporadic VS between April 2008 and June 2014 at the Department of Otolaryngology of the Hospital Universitario Ramón y Cajal were retrospectively reviewed. Patients that underwent other type of approach for tumour removal (retrosigmoid (RSG) approach or middle fossa (MF) approach) were excluded. Surgical approach was elected based on tumour characteristics, such as size and extension within the internal auditory canal, and factors related to the patient, such as age and preoperative hearing. In this case, the follow-up protocol of our centre includes MRI at 1, 3 and 5 years postoperatively ${ }^{11}$.

Patients were classified into 3 groups depending on the intensity of the cochlear signal of the surgical side compared to the contralateral cochlea. A patent cochlea (Fig. 1A) was considered when its T2-hyperintensity was homogeneous to the contralateral side. When there was no T2-hiperintensity signal of the cochlea, it was considered as a totally obliterated cochlea (Fig. 1B). Those cases that presented T2-hyperintensity signal, but in a lower fashion than the normal cochlea, with or without filling defect, were considered as partially obliterated cochlea (Fig. 1C). The relation between the degree of cochlear ossification in these three categories and the interval between surgery and the first MRI was studied. A secondary analysis was performed dividing the patients into 3 categories according to the time interval between surgery and the first MRI ( $<1$ year, 1-2 years and $>2$ years).
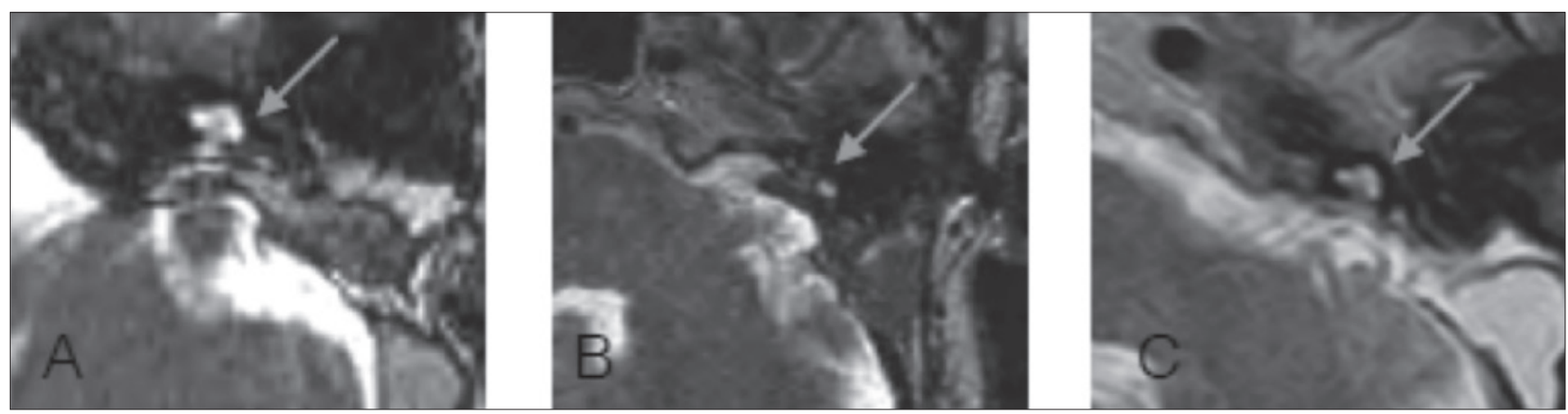

Fig. 1. T2 weighted temporal bone MRI, axial cuts at the level of the cochlea showing normal cochlear patency (A), totally obliterated cochlea (B) and partially obliterated cochlea $(\mathrm{C})$. 


\section{Statistical analysis}

Data was analysed with a statistical software program (SPSS Statistics for Windows version 20, Chicago, IL). Continuous data was summarised as mean $+/-95 \%$ confidence interval (CI95). Categorical data was presented as frequencies and percentages. Kolmogorov-Smirnov test demonstrated non-parametric distribution of the sample. The relation between cochlear patency and the interval between surgery and first MRI was studied with KruskalWallis test and Fisher's exact test. P values $<0.05$ were considered significant.

\section{Results}

Of the initial 69 patients, MRI examination was available for 41 patients. The mean age of the patients at the time of the surgery was 52.73 years, ranging from 24 to 80 years. 24 patients were women $(58.5 \%)$ and the remaining 17 were male $(41.5 \%)$. There was a predominance of left VS 27 (65.9\%) versus right VS 14 (34.1\%). The mean interval from surgery to the first MRI scan was 20 months (IC 95\% 16-23).

Of the 41 cochleae examined at the first MRI, 32 (78\%) presented some degree of obliteration; 14 (34\%) of them were totally obliterated cochleae and $18(44 \%)$ of them were partially obliterated cochleae. The remaining 9 cases $(22 \%)$ showed a T2-hyperintensity homogenous to the contralateral side and were considered as patent cochleae. No statistically significant differences were found between groups ( $\mathrm{p}>0.05)$.

In order to establish whether the interval between surgery and the first MRI has any impact on the cochlear obliteration rate, we calculated the mean interval between surgery and the first radiological image of the 3 different groups of cochlear patency previously described. The mean interval was 690 days (95\% CI 417-962) for the total obliteration group, 622 days (95\% CI 490-753) for the partial obliteration group and 434 days (95\% CI 271-596) for the patent cochlear group (Fig. 2). No statistically significant differences were found ( $\mathrm{p}>0.05)$.

When the patients were divided according to the interval between surgery and the first MRI, a tendency can be distinguished. Those who underwent the first MRI before completing the first year after surgery, 12 patients, tended to present a higher percentage of patent cochlea, whether those patients who underwent the first MRI after the first year, 29 patients, showed some degree of obliteration of the cochlea with a higher frequency (Fig. 3). In that sense, we can infer that the obliteration of the cochlea may be a time-depending process even though no statistically significant differences were found ( $p>0.05)$.

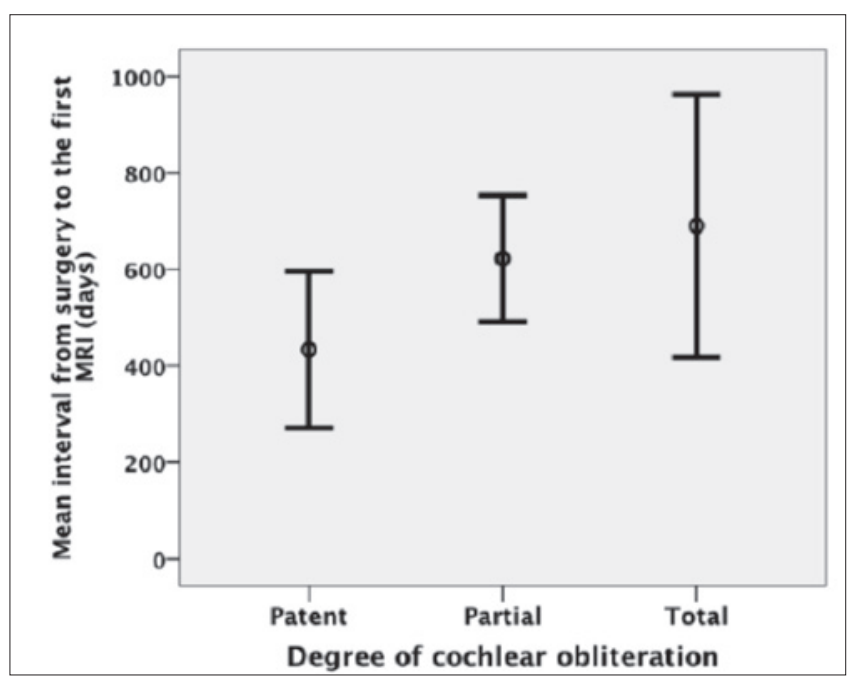

Fig. 2. Error bar diagram showing the mean interval of time from surgery to first MRI according to the clarification of cochlear potency.

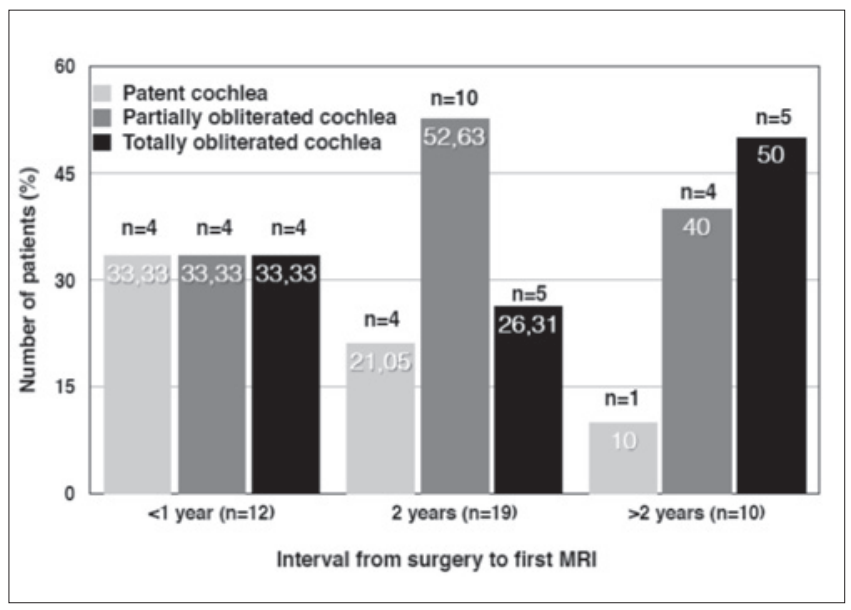

Fig. 3. Bar diagram showing the cochlear status depending on the time interval between surgery and first MRI.

\section{Discussion}

Surgical treatment of VS has evolved considerably over the past decades. Today, life-threatening complications secondary to surgery are rare; nevertheless, patients may experience different physical impairments that have a negative impact on their quality of life, such as facial palsy, vestibular disorders, persistent operative headache or more frequently, profound hearing loss ${ }^{12} 13$. Moreover, some surgical approaches invariably entail specific sequelae, such as complete hearing loss for the TLA. In case of a RSG or MF approaches, no insult to the otic capsule is encountered, and therefore hearing function can be theoretically preserved without any morphological changes within this structure. However, if hearing loss takes place after hearing preservation surgery, CI has been reported to be successful after retrosigmoid approach ${ }^{14}$. 
Cochlear implantation is the standard hearing rehabilitation procedure in cases of profound hearing loss, offering excellent results regardless of the age of subjects ${ }^{7}$. CI indications have progressively expanded over the years, from both the audiological and surgical points of view. More recently, new surgical approaches have been introduced in combination with CI, such as subtotal petrosectomy or skull base approaches, which allow implantation in cases formerly considered as non-candidates ${ }^{15} 16$. Hearing rehabilitation with a CI simultaneously to a VS resection was first described in 1995 by Arriaga and Marks ${ }^{17}$. Since then, publications of CI after VS resection have been increasing progressively, either simultaneously to tumour resection ${ }^{18} 19$ or delayed implantation ${ }^{20}$, and more recently in cases of single sided deafness (SSD ) ${ }^{2122}$. CI has also been employed for hearing rehabilitation after labyrinthectomy for Meniere's disease with different degrees of success, either simultaneously to labyrinthectomy or in a second procedure ${ }^{23}$. In both clinical scenarios, those who are prone to simultaneous implantation allege the risk of cochlear ossification after labyrinthectomy as one of the main reason to support this attitude. Since CI insertion depends on the feasibility of the electrode insertion and the integrity of the neural pathway, both conditions should be present to obtain useful hearing in any case.

However, the relation between cochlear ossification and time after the surgical procedure is not well defined in the literature, and there is not an established time frame to perform the CI insertion. To ensure cochlear patency, some authors suggest placing an intracochlear placeholder to avoid cochlear obliteration following the TLA ${ }^{22}$. This approach also permits radiological follow-up with MRI in case that residual tumour or tumour recurrence is suspected, which is estimated in up to $9 \%{ }^{24}$ in some series.

Currently, only two studies have attempted to determine the time in which the cochlear obliteration occurred after TLA, with different results. Beutner et al. ${ }^{25}$ determined the rate of cochlear obliteration presented on 14 patients who underwent a TLA. This study found that the rate of cochlear obliteration increased to $88.9 \%$ of patients at 1 year after surgery. Interestingly, some degree of cochlear obliteration was found in $66.7 \%$ of the sample as soon as 3 months after surgery.

On the contrary, the obliteration rate found by Charlett et al. ${ }^{26}$ was significantly lower. In this study, 65 cochlear were examined based on T2-weighted images one year after the TLA. On 44 cochleae (68\%) no sign of obliteration was found. The remaining 21 cochleae presented either complete $(14 \%)$ or partial obliteration $(18 \%)$.

Since the aetiology of cochlear obliteration is yet to be revealed, it is difficult to determine the circumstances to explain the difference in the obliteration rate of both studies. In our series, $78 \%$ of patients presented some degree of cochlear obliteration in the first follow-up MRI, and this rate is more similar to that presented by Beutner et al. However, our mean interval from surgery to MRI was longer than in studies described previously (20 months with $95 \%$ of the patients between 16 and 23 months). This longer interval could definitely influence the high degree of cochlear ossification found in the present study. Additionally, in our series there is a relation between the interval from surgery to the first MRI and cochlear obliteration rate, with a higher interval in cases showing a total obliteration, followed by the group with partial obliteration. The group with complete cochlear patency presented the lower time interval. Although these differences were not statistically significant, a temporal pattern can be identified. This supports the theory that cochlear obliteration is a time-dependent process that hampers $\mathrm{CI}$ insertion but that may be avoided with early CI placement or an intracochlear placeholder.

CI has been demonstrated to be a successful method for hearing rehabilitation after labyrinthectomy and TLA VS removal, being an effective alternative to the most classical auditory rehabilitation devices for SSD ${ }^{27}$. Even though the cases illustrated in the literature to date are scarce, auditory outcomes are promising when appropriate selection and counseling is performed 212829 . In this sense, it becomes critical to determine the time frame between the surgery and the beginning of the degenerative process. The present study found a rate of $78 \%$ in a sample of patients with an MRI obtained at a mean interval of 20 months after surgery, showing a temporal tendency to a higher degree of cochlear ossification with longer time interval. However, prospective studies are needed to clearly establish a "safe" time interval for cochlear implantation.

\section{Conclusions}

Surgical labyrinthectomy generates changes in cochlear histology that drive obliterative process. The interval between the surgery and the occurrence of the obliteration is still unknown, and so, the aetiology behind it also remains unclear. The present study found a rate of $78 \%$ in a sample of patients with an MRI obtained in a mean interval of 20 months after surgery, showing a temporal tendency to a higher degree of cochlear ossification with longer time interval. This fact limits the auditory rehabilitation process in cases when a CI is to be considered in a second surgery. Since a "safe" frame time between surgery and cochlear implantation has not yet been stablished, simultaneous cochlear implantation or an intracochlear placeholder is recommended.

\section{References}

1 Kim HJ, Jin Roh K, Oh HS, et al. Quality of life in patients 
with vestibular schwannomas according to management strategy. Otol Neurotol 2015;36:1725-9.

2 Chen DA, Linthicum FH Jr, Rizer FM. Cochlear histopathology in the labyrinthectomized ear: implications for cochlear implantation. Laryngoscope 1988;98:1170-2.

3 Son HJ, Choo D. Optimal management of single-sided deafness. Laryngoscope 2013;123:304-5.

4 Durisin M, Bartling S, Arnoldner C, et al. Cochlear osteoneogenesis after meningitis in cochlear implant patients: a retrospective analysis. Otol Neurotol 2010;31:1072-8.

5 Wang L, Zhang D. Surgical methods and postoperative results of cochlear implantation in 79 cases of ossified cochlea. Acta Otolaryngol 2014;134:1219-24.

6 Wang L, Zhang D. Cochlear implantation surgery in patients with totally ossified cochlea. Chin Med J 2014;127:3832-4.

7 De Seta D, Mancini P, Russo FY, et al. 3D curved multiplanar cone beam CT reconstruction for intracochlear position assessment of straight electrodes array. A temporal bone and clinical study. Acta Otorhinolaryngol Ital 2016;36:499-505.

8 Isaacson B, Booth T, Kutz JW Jr, et al. Labyrinthitis ossificans: how accurate is MRI in predicting cochlear obstruction? Otolaryngol Head Neck Surg 2009;140:692-6.

9 Tamplen M, Schwalje A, Lustig L, et al. Utility of preoperative computed tomography and magnetic resonance imaging in adult and pediatric cochlear implant candidates. Laryngoscope 2016;126:1440-5.

10 Marsot-Dupuch K, Meyer B. Cochlear implant assessment: imaging issues. Eur J Radiol 2001;40:119-32.

11 Roche PH, Ribeiro T, Khalil M, et al. Recurrence of vestibular schwannomas after surgery. Prog Neurol Surg 2008;21:89-92.

12 Medina MD, Carrillo A, Polo R, et al. Validation of the Penn Acoustic Neuroma Quality-of-Life Scale (PANQOL) for Spanish-speaking patients. Otolaryngol Head Neck Surg 2017;156:728-34.

13 McLaughlin EJ, Bigelow DC, Lee JY, et al. Quality of life in acoustic neuroma patients. Otol Neurotol 2015;36:653-6.

14 Dagna F, Murri A, Albera R, et al. Cochlear implantation in delayed sudden hearing loss after conservative vestibular schwannoma surgery. Acta Otorhinolaryngol Ital 2016;36:428-30.

15 Polo R, Del Mar Medina M, Arístegui M, et al. Subtotal petrosectomy for cochlear implantation: lessons learned after 110 cases. Ann Otol Rhinol Laryngol 2016;125:485-94.

16 Medina M, Di Lella F, Di Trapani G, et al. Cochlear implantation versus auditory brainstem implantation in bilateral total deafness after head trauma: personal experience and review of the literature. Otol Neurotol 2014;35:260-70.
17 Arriaga MA, Marks S. Simultaneous cochlear implantation and acoustic neuroma resection: imaging considerations, technique, and functional outcome. Otolaryngol Head Neck Surg 1995;112:325-8.

18 Arístegui M, Denia A. Simultaneous cochlear implantation and translabyrinthine removal of vestibular schwannoma in an only hearing ear: report of two cases (neurofibromatosis type 2 and unilateral vestibular schwannoma). Otol Neurotol 2005;26:205-10.

19 Ahsan S, Telischi F, Hodges A, et al. Cochlear implantation concurrent with translabyrinthine acoustic neuroma resection. Laryngoscope 2003;113:472-4.

20 Tono T, Ushisako Y, Morimitsu T. Cochlear implantation in an intralabyrinthine acoustic neuroma patient after resection of an intracanalicular tumor. Adv Otorhinolaryngol 1997;52:155-7.

21 Sanna M, Medina MD, Macak A, et al. Vestibular schwannoma resection with ipsilateral simultaneous cochlear implantation in patients with normal contralateral hearing. Audiol Neurootol 2016;21:286-95.

22 Hassepass F, Arndt S, Aschendorff A, et al. Cochlear implantation for hearing rehabilitation in single-sided deafness after translabyrinthine vestibular schwannoma surgery. Eur Arch Otorhinolaryngol 2016;273:2373-83.

23 Facer GW, Facer ML, Fowler CM, et al. Cochlear implantation after labyrinthectomy. Am J Otol 2000;21:336-40.

24 Schwartz MS, Kari E, Strickland BM, et al. Evaluation of the increased use of partial resection of large vestibular schwanommas: facial nerve outcomes and recurrence/regrowth rates. Otol Neurotol 2013;34:1456-64.

25 Beutner C, Mathys C, Turowski B, et al. Cochlear obliteration after translabyrinthine vestibular schwannoma surgery. Eur Arch Otorhinolaryngol 2015;272:829-33.

26 Charlett SD, Biggs N. The prevalence of cochlear obliteration after labyrinthectomy using magnetic resonance imaging and the implications for cochlear implantation. Otol Neurotol 2015;36:1328-30.

27 Vlastarakos PV, Nazos K, Tavoulari EF, et al. Cochlear implantation for single-sided deafness: the outcomes. An evidence-based approach. Eur Arch Otorhinolaryngol 2014;271:2119-26.

28 Schutt CA, Kveton JF. Cochlear implantation after resection of an intralabyrinthine schwannoma. Am J Otolaryngol 2014;35:257-60.

29 Lloyd SK, Glynn FJ, Rutherford SA, et al. Ipsilateral cochlear implantation after cochlear nerve preserving vestibular schwannoma surgery in patients with neurofibromatosis type 2. Otol Neurotol 2014;35:43-51.

Received: April 18, 2016 - Accepted: June 6, 2017

Address for correspondence: Beatriz Delgado-Vargas, Department of Otolaryngology and Head and Neck Surgery, Hospital Universitario Ramón y Cajal, Ctra de Colmenar Viejo, km 9,100, 28034 Madrid, Spain. E-mail: beatriz.delgadov9@gmail.com 